\title{
Causes of Burns in Patients Referred to a Large Burn Center
}

\author{
Sara Sheikh ${ }^{1}$, Zainab Poudineh², Zahra Abdi ${ }^{3}$ \\ ${ }^{1}$ Department of Burn Accidents, Community Nursing Research Center, Zahedan University of Medical \\ Sciences, Zahedan, Iran. ${ }^{2}$ Department of Burn Accidents, Community Nursing Research Center, \\ Zahedan University of Medical Sciences, Zahedan, Iran. ${ }^{3}$ Department of Burn Accidents, BSN, \\ Community Nursing Research Center, Zahedan University of Medical Sciences, Zahedan, Iran.
}

\section{ABSTRACT}

\section{BACKGROUND}

Burn is a type of skin injury or injury of mucous membranes caused by excessive heat or cold, chemicals, and electric current. Due to cultural, social, and climatic differences in different communities, different risk factors can involve in burns. The most important method of accident prevention is firstly acquiring information on the causes of accidents. In Iran, injuries due to burns are one of the most important causes of death which in turn is due to complications leading to malfunction and malformation of the burned organ. It also causes psychological problems. Thus, determining the causes and factors of burns is an important factor in determining prognosis, outcome, and mortality of patients. Therefore, this study aimed at investigating the burn related factors in Ali Ebne Abitaleb Hospital in Zahedan in 2018.

\section{METHODS}

This descriptive cross-sectional study was performed on burn patients in 2018 . Data were collected using the questionnaire and analysed by SPSS 16 software. The relationship between the cause of burns and various demographic and clinical variables was investigated. Inclusion criteria included age 6 to 18 years and seconddegree and third-degree burns. Demographic and clinical data of patients including sex, age, cause of burns, degree of burns and percentage of burns were recorded.

\section{RESULTS}

The average burn percentage in patients admitted to the emergency department was $24 \%$ and most of the burns were with boiling water of second-degree type. The most common burn areas were in the lower limbs, upper limbs, trunk, head, and neck, in that order. Among the individual factors, age, and among family factors, maternal education, fathers of education, and monthly income level were found to be important. According to the present study, the highest incidence of burns was seen in uneducated patients, and among patients with addiction.

\section{CONCLUSIONS}

In most parts of the world, burn with boiling water is the most common cause of hospitalization among burn patients. In this study, the relationship between the cause of burns, percentage of burns, and costs are the major determinants of outcome. In addition, the association of other demographic, psychological, and social factors such as age, gender, income, educational attainment, and addiction may also influence because occurrence of burn was more common in families with low education and income. As a result, many cases of burns can be prevented by identifying at-risk families and teaching them how to prevent burns.

\author{
Corresponding Author: \\ Zainab Poudineh, \\ MSN, Pediatric Nursing, \\ Community Nursing Research Center, \\ Zahedan University of Medical Sciences, \\ Zahedan, Iran. \\ E-mail: poodineh_68_z@yahoo.com
}

DOI: 10.14260/jemds/2020/395

Financial or Other Competing Interests: None.

How to Cite This Article:

Sheikh S, Poudineh Z, Adbi Z. Causes of burns in patients referred to a large burn center. J. Evolution Med. Dent. Sci. 2020;9(24):1809-1812, $10.14260 /$ jemds $/ 2020 / 395$

Submission 04-02-2020,

Peer Review 21-05-2020,

Acceptance 27-05-2020,

Published 15-06-2020.

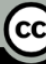

\section{KEY WORDS}

Epidemiology, Related Factors, Burns 


\section{BACKGROUND}

Burns are a type of injury caused by heat, chemical or electrical contact that can cause proteinuria, oedema and decreased extracellular fluid.[1] The World Health Organization reports in 2011 that more than 300,000 people per year die from Burns worldwide, with 95 percent of them in developing countries.[2] The number of burns in Iran with a population of 75 million is 150,000 annually, while in the United States with a population of 320 million it is 500,000, which indicates that the number of burns in our country is very high. In addition, about 3,000 people die each year from burns in the country, which has reached up 2,000 in recent years.[1]

Burn injuries are one of the leading causes of death in developed and developing countries, causing significant financial and life damage to patients and their families in different communities, ${ }^{[3,4]}$ while the death rate resulting from burns in low- and middle-income countries are 11 times higher than in high-income countries. ${ }^{[5]}$

Burn injuries require intensive care, prolonged hospitalization and a variety of treatments in comparison with other physical injuries in children.[6] In addition, burnrelated complications can result in malfunction and deformity of the burned organ and mental health problems in children and adolescents, and makes their future more difficult.[7] Various studies have shown that the cause of burns is an important factor in determining a patient's prognosis. For example, a study by Nursal et al. found that the most common cause of burns was electric burns, which had the lowest mortality, while, the flame burn was the leading mortality factor. ${ }^{[8]}$ In a study by Maghsoudi et al., flame burn was the most common cause of burns in children younger than 14 years, whereas in children younger than 5 years, boiling water was the most common cause of burn, and the average burn rate in this study was $19 \% . .^{[9]}$ In another study by Groohi et al., he level of burn patients was on average $40 \%$.[10]

Due to cultural, social, and climatic differences in different communities, different risk factors can contribute to burns and since the most important method of preventing accidents is firstly to obtain information on the causes and factors of accidents, and since providing and equipping burn health centers and proper planning to reduce complications requires information on the causes of burns so that burn injuries are prevented that include loss of function and burned organ deformity and psychological problems. Prevention and in Iran these injuries are one of the most important causes of morbidity and mortality due to complications. In Iran, also these injuries are among the major mortality factors due to the complication. Thus, determination of causes and factors related to burns are important factors in determining prognosis, outcome, and mortality of patients. Therefore, current study aimed at investigating the factors related to burns at Ali Ebne Abitaleb Hospital affiliated to Zahedan University of Medical Sciences (2018).

\section{METHODS}

This is a descriptive cross-sectional study that was carried out on burn patients referred to the emergency department of Ali Ebne Abitaleb Hospital in Zahedan.

Ali Ebne Abitaleb Hospital is affiliated to Zahedan University of Medical sciences and has been ranked among top hospitals of Iran by the Ministry of Health, Treatment and Medical education. Convenience sampling method was used. The research subjects were explained about the research purpose, and they were reminded that their information will be kept confidential and they participated with informed consent. Inclusion criteria included age 6 to 18 years with second-degree and third-degree burns, and exclusion criteria were reluctance for participation in the project. Demographic and clinical data of patients including sex, age, income, and education of parents, cause of burn, degree of burn, percentage of burn, and burn areas were recorded. Data were analysed by SPSS software version 16 and data were analysed using frequency, percentage, mean, and standard deviation indexes.

\section{RESULTS}

In this study, 317 patients were studied. Findings demonstrated that $164(54.66 \%)$ of subjects were male. Overall, $76.68 \%$ of the subjects had second-degree burn (table 1).

\begin{tabular}{|cccc|}
\hline Variable & Sub-Group & No. & \% \\
Gender & Male & 164 & $66 / 54$ \\
& Female & 153 & $33 / 51$ \\
& Boiling water & 143 & $66 / 47$ \\
Cause of burn & Flame & 84 & 28 \\
& Chemicals & 56 & $66 / 18$ \\
& Electric current & 22 & $33 / 7$ \\
& Other & 8 & $66 / 2$ \\
Degree of burn & Second-degree & 218 & $76 / 68$ \\
& Third-degree & 99 & $23 / 31$ \\
& Lower extremities & 166 & $36 / 52$ \\
& Upper extremities & 76 & $97 / 23$ \\
& Trunk & 48 & $14 / 15$ \\
& Head and neck & 21 & $62 / 6$ \\
& Perineum & 6 & $89 / 1$ \\
\hline & Table 1. Clinical Information of Patients \\
\hline
\end{tabular}

The mean burn rate in burn patients referred to burn emergency ward was $24.6 \%$. The highest average burns occurred in elementary school children. The most common cause of burns was boiling water $(66 / 47 \%)$. The most common burn areas were in the lower extremities (52.36\%) and upper extremity, trunk, head and neck and perineum respectively, which are summarized in Table 1.

Among the individual factors, age and among family factors, mother's education, father's education, and monthly income level can be considered as factors affecting occurrence of burns. According to the present study, the highest incidence of burn occurs in uneducated parents, with low income levels and addicted mothers (table 2). 


\begin{tabular}{|cccc|}
\hline Variable & Sub-Group & No. & \% \\
& Illiterate & 137 & $21 / 43$ \\
Mother's education & Below high school & 106 & $43 / 33$ \\
& BA & 56 & $66 / 17$ \\
& Above BA & 18 & $67 / 5$ \\
& Illiterate & 136 & $90 / 42$ \\
Father's education & Below high school & 144 & $42 / 45$ \\
& BA & 14 & $41 / 4$ \\
& Above BA & 23 & $25 / 7$ \\
Income level & low-income & 214 & $5 / 67$ \\
& middle-income & 55 & $35 / 17$ \\
& High-income and & 48 & $14 / 15$ \\
& above & 139 & $84 / 43$ \\
Parental addiction & Mother's addiction & 62 & $55 / 19$ \\
& Father's addiction & 109 & $38 / 34$ \\
& Addiction of both & parents & 7 \\
\hline & Non-addicted & $20 / 2$ \\
\hline \multicolumn{2}{c}{ Table 2. Demographic Information of Patients } \\
\hline
\end{tabular}

\section{DISCUSSION}

In this study, which examined demographic and clinical data of burn cases in patients admitted to Ali Ebne Abitaleb Hospital's emergency department in Zahedan, the results showed that although the prevalence of burns among boys and girls was approximately the same, the burn rate in boys (54.66) was slightly higher. In a study by Thin and Uygur, burns were more in boys than in girls, which was consistent with the present study.[11,12] One of the major causes of increased burn in boys than girls is the greater courage of boys than girls to do dangerous works.[13] According to Hakimi et al., young boys are more likely to be burned because of their parents' negligence.[5] Based on the results of Kumar et al., investigating epidemiological causes of burns in children, it was shown that most $(70.1 \%)$ cases were children less than 5 years of age.[14] However, in the present study, because of the inclusion criteria of 6 to 18 old, it was shown that burns were higher in elementary school age, with an average of 8.1 years, which could be due to increased children's risk because of curiosity and wrong understanding of threats.

In the present study, as in many studies, ${ }^{[15-18]}$ the most common causes of burns were with boiling water. There was a significant difference between burn victim and age in the study by Ghorbani et al., so that the burn factor in age range of below 14 years was mostly boiling water and hot liquids, and the burn factor in the age group of over 14 years was fire, which is consistent with the results of the present study.[19]

In this study, higher incidence of burns in the lower extremities compared to other organs is observed, while the studies by Nguyen et al. and Chen et al. showed that most of the burns were in the upper extremities.[20,21] It seems that according to the Iranian culture that the food or tea is served on the rugs; it is a factor that causes injury to the child while walking and running. As a result, burns in the lower extremities are more common in Iran, while in other countries, where tableware and chairs are used for serving food, burn in upper extremities is more common. The present study also showed that most of the burn cases occur in people with low level of education and income and those with a history of addiction especially in the mother of the family This clearly illustrates the effect of increased awareness and information on avoiding risk factors and risky situations, and perhaps one of the reasons for the decrease rate of burn in people with academic education is their occupation in lower- risk jobs and appropriate performance in relation to high-risk situations. A study by Amir Alavi et al showed that less than $3 \%$ of hospitalized patients had academic education; most of patients had high school degree and the rest were illiterate to primary school education.[22] In the study by Khorasani et al., $65 \%$ of patients were illiterate. It also showed that there is a significant relationship between education level and the cause of burns.[23] According to a study by Green et al., population density, poverty, and low education were among the risk factors for burns in children. ${ }^{[24]}$ Hope in god and have positive psycho logy are beneficial to alleviate the pain and stress as Ebadi et al. concluded that spirituality is a pivotal factor for the acceptance and adjustment and they expressed that spiritual adaptive strategies help patients to find meaning and goals during their illness. ${ }^{[25,26]}$

In developing countries, promoting socioeconomic status is considered to be the first strategy to prevent burn,[27] and as addiction is one of the consequences of poverty in lowincome communities, controlling it can play an important role in prevention of burn.

\section{CONCLUSIONS}

In this study, the cause of burns, percentage of burns, and the degree of burns are the major determinants of outcome. In addition, the association of other demographic, psychological, and social factors such as age, sex, income level, educational attainment, and addiction can also influence because the incidence of burn was higher in families with low educationand income-levels. As a result, many burn cases can be prevented by identifying at-risk families and training burn prevention techniques. In addition, the findings of this study can provide insights into ways to apply preventive methods to reduce burn and its resulting injuries. That is, implementation of various educational preventive programs for parents, especially for mothers and children at home, school, workplace, public media, and social networks along with training in use of first aid kits, proper use of equipment, and observing home safety tips are effective in reducing the incidence of burns in society. Observing the above cases and thoroughly identifying the risk factors and factors associated with burns can help reduce the physical, psychological, and socioeconomic effects of burns.

\section{REFERENCES}

[1] Azizi AA, Zarei J, Nabovati E, et al. Determining of the factors affecting mortality in burn patients using a decision tree data mining algorithm. J Health Admin 2014;16(54):34-45.

[2] World Health Organization. Burn Prevention Success Stories Lessons Learned. Geneva: Switzerland: WHO, 2011.

[3] Atiyeh B, Costagliola M, Hayek SN. Burn prevention mechanisms and outcomes: pitfalls, failures and successes. Burns 2009;35(2):181-93.

[4] Wasiak J, Spinks A, Ashby K, et al. The epidemiology of burn injuries in an Australian setting, 2000-2006. Burns 2009;35(8):1124-32. 
[5] Hakimi H, Shafipoor SZ, Leili EKN, et al. Characteristics of burn children in Guilan Province. JHNM 2012;22(1):915.

[6] Emmitsburg MD. Fire in the United States 1987-1996. $11^{\text {th }}$ edn. United States Fire Administration, Federal Emergency Management Agency, 1999.

[7] Holmes JH, Heimbach DM. Burns. In: Brunicardi FC, Anderson DK, Billiar TR, et al. eds. Schwartz's Principles of surgery. Columbus, USA: The McGraw-Hill Companies Inc., 2005: p. 55-62.

[8] Nursal TZ, Yildirm S, Tarim A, et al. Burn in southern Turkey: electrical burns remain a major problem. J Burn Care Rehabil 2003;24(5):309-14.

[9] Maghsoudi H, Samnia N. Etiology and outcome of pediatric burns in Tabriz, Iran. Burns 2005;31(6):721-5.

[10] Groohi B, Alaghehbandan R, Lari AR. Analysis of 1089 burn patients in province of Kurdistan, Iran. Burns 2002;28(6):569-74.

[11] Thin MM, Lee BW, Bun PY. Childhood injuries in Singapore: a community nationwide study. Singapore Med J 2005;46(3):116-21.

[12] Uygur F, Sahin C, Duman H. Analysis of pediatric burns in a tertiary burns center in Istanbul, Turkey. Eur J Pediatr Surg 2009;19(3):174-8.

[13] Behrman RE, Kligman RM, Jenson HB. Nelson Text book of Pediatrics. Philadelphia: W.B. Saunders Co, 2000: p. 233.

[14] Kumar P, Chirayil PT, Chittoria R. Ten years epidemiological study of pediatric burns in Manipal, India. Burns 2000;26(3):261-4.

[15] Pegg SP. Burn epidemiology in the Brisbane and Queensland area. Burns 2005;31(Suppl 1):S27-S31.

[16] Chien WC, Pai L, Lin CC, et al. Epidemiology of hospitalized burns patients in Taiwan. Burns 2003;29(6):582-8.
[17] Soltani K, Zand R, Mirghasemi A. Epidemiology and mortality of burns in Tehran, Iran. Burns 1998;24(4):325-8.

[18] Panjeshahin M, Lari RA, Talei A, et al. Epidemiology and mortality of burns in the South West of Iran. Burns 2001;27(3):219-26.

[19] Ghorbani F, Shiri M, Ghasemi MM, et al. Epidemiologic study of burn patients hospitalized in Mousavi Hospital, Zanjan 2010-2012. Preventive Care in Nursing and Midwifery Journal (PCNM) 2016;5(2):65-74.

[20] Chen XL, Guo F, Liang X, et al. Burns caused by alcoholbased fires in the household coal stove in Anhui Province, China. 2010;36(6):861-70.

[21] Nguyen DQ, Tobin S, Dickson WA, et al. Infants under 1 year of age have a significant risk of burn injury. Burns 2008;34(6):863-7.

[22] Alavi AS, Reza MM, Tolouei M, et al. Epidemiology and outcome of burn injuries in burn patients in Guilan province, Iran. Qom Univ Med Sci J 2013;7(5):35-41.

[23] Khorasani GH, Slehifar E, Eslami G. Causes of burns and their outcomes in patients hospitalized in burn division of Zare hospital 2006-2007. J Mazandaran Univ Med Sci 2007;17(61):122-30.

[24] Green AR, Fairclough J, Skype PJ. Epidemiology of burns in childhood. Burns Incl Therm Inj 1984;10(5):368-71.

[25] Ebadi A, Ahmadi F, Ghanei M, et al. Spirituality: a key factor in coping among Iranians chronically affected by Mustard gas in the disaster of war. Nurs Health Sci 2009;11(4):344-50.

[26] Rahnama M, Khoshknab MF, Maddah SSB, et al. Religion as an alleviating factor in Iranian cancer patients: a qualitative study. Asian Pacific Journal of Cancer Prevention 2015;16(18):8519-24.

[27] Daisy S, Mostaque AK, Bari TS, et al. Socioeconomic and cultural influence in the causation of burns in the urban children of Bangladesh. J Burn Care Rehabil 2001;22(4):269-73. 